\title{
Osteoporosis Health Beliefs, Knowledge and Life Habits among Women in Saudi Arabia
}

\author{
Hala Hazam Al-Otaibi \\ Department of Food Sciences and Nutrition, King Faisal University, Al-Ahsa, Saudi Arabia \\ Email: halaalotaibi5m@gmail.com, hhalotaibi@kfu.edu.sa
}

Received 5 May 2015; accepted 6 June 2015; published 9 June 2015

Copyright (C) 2015 by author and Scientific Research Publishing Inc.

This work is licensed under the Creative Commons Attribution International License (CC BY).

http://creativecommons.org/licenses/by/4.0/

\section{(c) (i) Open Access}

\begin{abstract}
Osteoporosis has been recognized as a major public health problem by healthcare providers in Saudi Arabia. The present study examines the osteoporosis knowledge, health beliefs, and some of the life habits in two different Saudi women's groups (with family history, and without family history), to find the association of their knowledge and health beliefs with their preventive practice. This is a descriptive cross-sectional study conducted among a convenience sample of 288 young age (20 to 40 years) women attending the health centers in Al-Hassa, Saudi Arabia. Both groups had an inadequate daily calcium intake with a significant difference between them. The women without family history had low mean of knowledge (8.9 \pm 2.7$)$ compared with family history group $(9.3 \pm 2.7)$ with a significant difference $(p=0.04)$. Based on the Osteoporosis Health Belief Scale (OHBS) subscale mean score, the perceived susceptibility and perceived severity were lower in women without family history with a significant difference between the groups $(\mathbf{p}=0.02,0.00$; respectively). The family history group had lower mean score barriers of calcium intake and exercise with a significant difference between groups $(p=0.017,0.013$; respectively). Statistically significant correlation was found between calcium intake and OHBS subscale perceived susceptibility, perceived severity, perceived benefits of calcium intake and exercise, and perceived barriers of exercise only for the family history group. This study indicates inadequate daily calcium intake, with moderate knowledge of osteoporosis in Saudi women and highlights the need for diet and life habits interventions to improve calcium intake and exercise, which may help to reduce the burden of osteoporosis in Saudi Arabia.
\end{abstract}

\section{Keywords}

Osteoporosis, Knowledge, Belief, Calcium, Life Habits

\section{Introduction}

Osteoporosis is a major public health problem in Saudi Arabia and the contributor of mortality and morbidity 
among elderly people [1] [2]. In a review of the published articles by Sadat-Ali and colleagues [2012], they estimated the prevalence of osteoporosis among Saudi women at $34 \%$. In community based screening study among 3269 healthy Saudi women aged between 29 - 56 years the authors reported incidence of osteopenia and osteoporosis between 23\% and 31\% [3]. According to the International Osteoporosis Foundation (IOF) reports, 1,461,401 Saudi persons aged 50 years or more, 8768 would suffer femoral fractures yearly at a cost of $\$ 1.14$ billion [4]. At $90 \%$ of peak bone mass is obtained in the age of 30 years (the child bearing age) and the best time to invest in bone health is before 30 [5]. After 30 years there is a $1 \%-2 \%$ decline in bone mass each year until menopause, in which $40 \%$ of their total bone mass decrease rapidly due to low estrogen levels [6].

Among Saudi women, osteoporosis is a multi factorial disease and the possible causes include: vitamin-D deficiency, sedentary lifestyle, low calcium intake, limited time to sun exposure, smoking, hormones, and genetic factors [1] [2]. Most of them modifiable factors with early assessment at an early age; we can avoid these risk factors [6] [7]. The first step in the prevention of osteoporosis in women should be to make them aware of the risk factors [8]. There is evidence that proves knowledge about osteoporosis contributor of preventive behavior [9], but some studies of women indicated that knowledge about osteoporosis risk factors is limited, irrespective of age [10]. Based on Barzanji et al. [11], there is a deficiency in knowledge and poor application of the preventive, health education is needed to improve knowledge and motivating healthy behaviors.

The Osteoporosis Health Belief Scale (OHBS) is one of the most widely used frameworks for trying to understand and measure health beliefs related to osteoporosis. It includes items addressing seriousness, susceptibility, calcium benefits, calcium barriers, exercise benefits, exercise barriers, and health motivation related to osteoporosis [12]. It is based on the premise that people are most likely to take health related actions (e.g., be active, eat a healthy diet), if they feel that by doing this action they can avoid a negative health condition. The objectives of this study were to investigate the knowledge, beliefs and behaviors about risk factors and preventive measures as calcium intake and exercise in young women in Saudi Arabia with and without a family history of osteoporosis.

\section{Material and Methods}

This is a descriptive cross-sectional study conducted from December 2014 to February 2015, a convenience sample of 288 young age (20 to 40 years) women attending the health centers in Al-Hassa, Saudi Arabia, were four health centers randomly selected for the study. Only apparently healthy women, not pregnant, non lactation were invited to participate with informed consent. Through structured interview each participant interviewed individually by the researcher, ethical approval was obtained from college of Agriculture and Food Science at King Faisal University.

\subsection{Instruments}

\subsubsection{Demographic Information}

Age, employment status, education level, history of osteoporosis in the family, marital status, and household income.

\subsubsection{Anthropometric Indicator and Lifestyle Habits of Subjects}

Height and weight were measured by researcher to calculate Body Mass Index (BMI) then classified according to World Health Organization guidelines [13]. Exercising (below 3 times/week, 3 times/week or more), smoking, daily exposing to sunlight, vitamin D and calcium supplement intake, history of fractures, and daily calcium intake was assessed by one day 24-hour recall method.

\subsubsection{The Osteoporosis Knowledge Assessment Tool (OKAT)}

It was developed by Winzwnberg et al. [9]. The instrument consists of four subscales addressing: understanding (symptoms and risk of fracture) five items, risk factors of osteoporosis seven items, prevention factors as physical activity and diet relating to osteoporosis six items, treatment availability two items. The format of the 20-item scale included the "true-false and don't know” options. The scores for knowledge were calculated based on one point for the correct answer and zero for the wrong answer or don't know the answer. The maximum scores for the total knowledge were twenty. The overall reliability of the OKAT based on Cronbach's alpha coefficient for the 20-items was 0.875 . 


\subsubsection{The Osteoporosis Health Belief Scale (OHBS)}

It was developed by Kim and colleagues [12] to measure health beliefs related to osteoporosis. It is a 42-item instrument consisting of seven subscales addressing health beliefs. The subscales address: susceptibility, severity, benefits to exercise, benefits to calcium intake, barriers to exercise, barriers to calcium intake, health motivation. The format of the scale 5 point Likert scale included "strongly agree, agree, disagree, strongly disagree and undecided". The score of five is to strongly agree, four to agree, three to undecided, two to disagree and one to strongly disagree. Possible range of 42 to 210 for the total health belief score. A possible range of 6 to 30 for each subscale score. Higher scores for barriers indicate more negative health beliefs, and the rest higher scores indicating highly healthy beliefs. The overall reliability of the OHBS based on Cronbach's alpha co-efficient for the 42 items was 0.895 .

\subsection{Data Analysis}

Data analyses were done using the statistical software program SPSS version 19. The data were presented in the form of frequencies, percentages, mean, standard deviation and analytical tests, including T-test, Chi square, and Pearson's correlation coefficient. The significance level was set at $\mathrm{p} \leq 0.05$.

\section{Results}

This study included 288 women who enrolled from four health centers. Table 1 present the distribution of the women according to family history of osteoporosis. Women with family history had mean aged $33.1 \pm 8.8$ years older than women without family history with significant difference $(p=0.007)$. A majority of both groups had a high level of education, married, not employed and had monthly income 5,000 Saudi Real or lower. Women with a family history of osteoporosis had a mean BMI (24.8 \pm 5.9$)$ more than the other group (22.4 \pm 4.5$)$ with a significant difference between them, almost $40 \%$ of women with a family history, overweight and more than half (58.5\%) of them exercised three times or less weekly and only $11.3 \%$ of them smoke with significant difference between the groups. However, the majority of gropes not daily exposed to sunlight despite of the history of fractures with a significant difference between them. Only $22.5 \%, 13.7 \%$ of women without a family history of osteoporosis take calcium and V.D as supplement respectively. Daily calcium intake was higher in a family history group with a significant difference between the groups $(\mathrm{p}=0.03)$ (Table 2$)$.

Table 1. Demographics characteristic of subjects.

\begin{tabular}{|c|c|c|c|}
\hline Variable & Family history n = $106(37 \%)$ & No family history $n=182(63 \%)$ & $\mathbf{p}$ \\
\hline \multicolumn{4}{|l|}{ Age } \\
\hline Mean (s.d) & $33.15 \pm 8.8$ & $27.57 \pm 6.9$ & 0.007 \\
\hline \multicolumn{4}{|l|}{ Education level } \\
\hline Secondary and lower & $23(21.7 \%)$ & $50(27.5 \%)$ & \multirow{2}{*}{0.27} \\
\hline University and higher & $83(78.3 \%)$ & $132(72.5 \%)$ & \\
\hline \multicolumn{4}{|l|}{ Employment status } \\
\hline Employed & $33(31.1 \%)$ & $40(22 \%)$ & \multirow{2}{*}{0.08} \\
\hline Not employed & $73(68.9 \%)$ & $142(87 \%)$ & \\
\hline \multicolumn{4}{|l|}{ Marital status } \\
\hline Single & $36(34 \%)$ & $76(41.8 \%)$ & \multirow{2}{*}{0.19} \\
\hline Married & $70(66 \%)$ & $106(58.2 \%)$ & \\
\hline \multicolumn{4}{|l|}{ Income (Saudi Real) } \\
\hline$\leq 5000$ & $63(59.4 \%)$ & $121(66.5 \%)$ & \multirow{2}{*}{0.23} \\
\hline$>5000$ & $43(40.6 \%)$ & $61(33.5 \%)$ & \\
\hline
\end{tabular}


Table 2. Anthropometric indicators and life habits of subjects.

\begin{tabular}{|c|c|c|c|}
\hline Variable & $\begin{array}{c}\text { Family history } n=106 \\
(37 \%)\end{array}$ & No family history $n=182(63 \%)$ & $\mathbf{p}$ \\
\hline Weight (kg) & $63.1 \pm 15.5$ & $55.9 \pm 11.4$ & $0.00^{* *}$ \\
\hline BMI $\left(\mathrm{kg} / \mathrm{m}^{2}\right)$, Mean (s.d) & $24.8 \pm 5.9$ & $22.4 \pm 4.5$ & $0.018^{*}$ \\
\hline <18.5 (underweight) & $6(5.7 \%)$ & $31(17 \%)$ & \\
\hline 18.5 - 24.9 (normal) & $58(54.7 \%)$ & $116(63.7 \%)$ & $0.00^{* *}$ \\
\hline 25 - 29.9 (overweight) & $42(39.6 \%)$ & 35 (19.3\%) & \\
\hline \multicolumn{4}{|l|}{ Exercises } \\
\hline$<3$ times/week & $62(58.5 \%)$ & $114(62.6 \%)$ & \multirow{2}{*}{$0.025^{*}$} \\
\hline$\geq 3$ times/week & $44(41.5 \%)$ & $68(37.4 \%)$ & \\
\hline \multicolumn{4}{|l|}{ Smoking } \\
\hline Yes & $12(11.3 \%)$ & $3(1.6 \%)$ & \multirow{2}{*}{$0.01^{*}$} \\
\hline No & $94(88.7 \%)$ & 179 (98.4\%) & \\
\hline \multicolumn{4}{|l|}{ Daily exposing to sun light } \\
\hline Yes & 27 (25.5\%) & $37(20.3 \%)$ & \multirow[t]{2}{*}{0.31} \\
\hline No & $79(74.5 \%)$ & $145(79.7 \%)$ & \\
\hline \multicolumn{4}{|l|}{ Calcium supplements user } \\
\hline Yes & $43(40.5 \%)$ & $41(22.5 \%)$ & \multirow{2}{*}{$0.04^{*}$} \\
\hline No & $63(59.5 \%)$ & $141(77.5 \%)$ & \\
\hline \multicolumn{4}{|l|}{ Vitamin D supplements user } \\
\hline Yes & $25(23.1 \%)$ & $25(13.7 \%)$ & \multirow{2}{*}{$0.023^{*}$} \\
\hline No & 81 (76.9\%) & $157(86.3 \%)$ & \\
\hline \multicolumn{4}{|l|}{ History of fractures } \\
\hline Yes & $33(31.1 \%)$ & $38(20.8 \%)$ & \multirow{2}{*}{0.12} \\
\hline No & $73(68.9 \%)$ & $144(79.2 \%)$ & \\
\hline Calcium (mg/day), Mean (s.d) & $789.94 \pm 461.4$ & $671.08 \pm 332.5$ & $0.03^{*}$ \\
\hline
\end{tabular}

${ }^{*} \mathrm{p}<0.05,{ }^{* *} \mathrm{p}<0.001$.

Table 3 presents the mean scores of OKAT among groups which demonstrates the deficient knowledge of the groups, while women without family history had low mean of knowledge $(8.9 \pm 2.7)$ compared to family history group $(9.3 \pm 2.7)$ with significant difference $(p=0.04)$. Based on the OHBS subscale mean score the perceived susceptibility and perceived severity were lower in women without family history compared to the other group with a significant difference ( $p=0.02,0.00$; respectively). Both groups had higher mean of benefit of calcium intake, exercise and health motivation without significant difference between groups. The family history group had lower mean score barriers of calcium intake and exercise with a significant difference between groups ( $\mathrm{p}=$ 0.017, 0.013; respectively).

Statistically significant correlation was found between calcium intake and OHBS subscale perceived susceptibility, perceived severity, perceived benefits of calcium intake and exercise, and perceived barriers of exercise only for family history group and the rest of subscale and knowledge was no significant correlation were found. Similarly, the no family history group, no significant correlation found for OHBS subscale and knowledge (Table 4).

\section{Discussion}

Osteoporosis has been recognized as a major public health problem by healthcare providers in Saudi Arabia. 
Table 3. Mean scores on the OHBM subscales and OKAT among the study subjects.

\begin{tabular}{cccc}
\hline Variable & $\begin{array}{c}\text { Family history } \\
\mathbf{n = 1 0 6} \mathbf{( 3 7 \% )}\end{array}$ & $\begin{array}{c}\text { No family history } \\
\mathbf{n = 1 8 2} \mathbf{( 6 3 \% )}\end{array}$ & $\mathbf{p}$ \\
\hline Knowledge (20 items) & $9.3 \pm 2.7$ & $8.9 \pm 2.7$ & $0.04^{*}$ \\
Perceived Susceptibility (Q1-6) & $17.7 \pm 5.1$ & $16.5 \pm 4.9$ & $0.02^{*}$ \\
Perceived Severity (Q7-12) & $18.3 \pm 4.8$ & $14.6 \pm 4.5$ & $0.00^{* *}$ \\
Perceived Benefits of exercises (Q13-18) & $21.1 \pm 5.4$ & $21.9 \pm 3.5$ & 0.19 \\
Perceived Benefits of calcium intake (Q19-24) & $21.8 \pm 4.5$ & $22.6 \pm 3.8$ & 0.16 \\
Perceived Barriers of exercises (Q25-30) & $16.4 \pm 4.1$ & $17.6 \pm 4.1$ & $0.017^{*}$ \\
Perceived Barriers of calcium intake (Q31-36) & $16.3 \pm 3.2$ & $17.1 \pm 3.6$ & $0.013^{*}$ \\
Motivation (Q37-42) & $21.9 \pm 4.2$ & $21.2 \pm 4.5$ & 0.16 \\
All items (Q1-42) & $133.5 \pm 14.3$ & $130.9 \pm 12.4$ & 0.187 \\
\hline
\end{tabular}

${ }_{\mathrm{p}}^{*}<0.05,{ }^{* *} \mathrm{p}<0.001$.

Table 4. The relationship between the OHBM subscales with daily Calcium intake of subjects.

\begin{tabular}{|c|c|c|c|}
\hline Variable & & $\begin{array}{l}\text { Family history } \\
n=106(37 \%)\end{array}$ & $\begin{array}{c}\text { No family history } \\
n=182(63 \%)\end{array}$ \\
\hline \multirow{2}{*}{ Knowledge (20 items) } & $\mathrm{r}$ & 0.08 & 0.14 \\
\hline & $\mathrm{P}$ & 0.42 & 0.05 \\
\hline \multirow{2}{*}{ Perceived Susceptibility (Q1-6) } & $\mathrm{r}$ & 0.02 & 0.12 \\
\hline & $\mathrm{P}$ & $0.02^{*}$ & 0.16 \\
\hline \multirow{2}{*}{ Perceived Severity (Q7-12) } & $\mathrm{r}$ & 0.25 & 0.11 \\
\hline & $\mathrm{P}$ & $0.04^{*}$ & 0.11 \\
\hline \multirow{2}{*}{ Perceived Benefits of exercises (Q13-18) } & $\mathrm{r}$ & 0.32 & 0.10 \\
\hline & $\mathrm{P}$ & $0.001^{* *}$ & 0.53 \\
\hline \multirow{2}{*}{ Perceived Benefits of calcium intake (Q19-24) } & $\mathrm{r}$ & 0.25 & 0.05 \\
\hline & $\mathrm{P}$ & $0.009^{* *}$ & 0.76 \\
\hline \multirow{2}{*}{ Perceived Barriers of exercises (Q25-30) } & $\mathrm{r}$ & -0.205 & -0.12 \\
\hline & $\mathrm{P}$ & $0.03^{*}$ & 0.08 \\
\hline \multirow{2}{*}{ Perceived Barriers of calcium intake (Q31-36) } & $\mathrm{r}$ & -0.11 & 0.13 \\
\hline & $\mathrm{P}$ & 0.25 & 0.06 \\
\hline \multirow{2}{*}{ Motivation (Q37-42) } & $\mathrm{r}$ & 0.11 & 0.06 \\
\hline & $\mathrm{P}$ & 0.23 & 0.36 \\
\hline
\end{tabular}

${ }^{*} \mathrm{p}<0.05,{ }^{* *} \mathrm{p}<0.001$

Sufficient information about women's knowledge, health beliefs, and some of the life habits are important to plan for the disease prevention. The present study examined the osteoporosis knowledge, health beliefs, and some of the life habits in two different Saudi women's groups (with family history, and without family history), to find the association of their knowledge and health beliefs with their preventive practice (calcium intake). Both groups had normal BMI and a majority of women in the normal category, almost 40\% of women with a family history, overweight which more than previous studies conducted among Saudi women (29\% to 33.5\%) at the same age [14] [15].

Optimal physical activities are necessary for increasing bone mass and reducing the risk of osteoporosis by improving bone mass. The majority of women had physical level at low level, resent studies among Saudi women reported similar to our finding were only $60 \%$ of women reported practicing exercise [16], another study 
conducted in middle age women (33 years) in Riyadh Saudi Arabia reported that few women (10\%) had adequate physical activities [11].

Smoking cigarettes in the present study was very low among women in both groups. It could be for Islamic reason, while smoking reduces bone mineral density by decreasing the amount of calcium absorbed from food [WHO, 2003]. In present study one quarter of women in both groups daily exposed to sunlight this may be due to the hot climate and the majority of them not employed. However, sunlight exposure is a natural source of vitamin D with 10 to 15 minutes is enough for human body produces adequate quantities of vitamin D. Generally Saudi women had low exposed to sunlight [11] [16].

Calcium and vitamin D supplementation reduces rates of bone loss and also fracture rates in adults. Women with family history had a significantly higher intake of calcium and V.D supplements that could be selves more they perceived themselves are more at risk of osteoporosis than women without a family history. Dietary calcium intake is an important nutrient for bone health, while calcium deficiencies in young women can increase the risk for hip fracture later in life and account for a 5\% to $10 \%$ difference in peak bone mass [17]. Our findings indicate they had a mean of dietary calcium intake less than the recommended level $1000 \mathrm{mg} /$ day [18] in both groups, but with a significant difference between the groups were women's family history group had higher mean intake ( $789 \mathrm{mg} /$ day) but still below the daily-recommended level, which put them under risk of osteoporosis. Similarly, non adequate dietary calcium intakes have been reported in women in previous studies among Iranian women (689 mg/day) [19], Sri Lankan women (528 mg/day) [20], or Chinese women (448 mg/day) [21].

Participants who had a family history of osteoporosis revealed a significantly higher score in comparison to without that history and both of them had a moderate level of knowledge. The effect of this factor on knowledge also was revealed by a study among Indian women [22]. Although, it was shown from a study by Hurst et al. [23] among New Zealand women that knowledge about osteoporosis, increased with increase in age, while women with family history was older than women without history of disease. This finding is similar to Rafraf et al. [24], who reported that $63.2 \%$ of women had low to moderate level of knowledge about osteoporosis prevention behaviors. Resent study conducted among 500 Saudi women revealed that two thirds of women have satisfactory knowledge scores toward osteoporosis and its prevention [16]. On the other hand, in contrast with previous study investigating osteoporosis knowledge amongst women with and without family history found women had limited knowledge of osteoporosis without significant difference in knowledge between them [25].

Women who have a family history of osteoporosis feel susceptible to osteoporosis, and thought osteoporosis to be moderately severe than women who do not have a family history of osteoporosis. However, women without family history they moderately believe that osteoporosis would affect their lives, but not with low severity affect. This is in agreement with those obtained by Gammage et al. [26] found that young women had higher perceived susceptibility and severity of osteoporosis. However, Edmonds et al. [27] found that women had low perceived susceptibility and a moderate perceived severity of osteoporosis. Chang [28] found that young women how had good knowledge of osteoporosis had high perceived susceptibility, a low perceived severity, and believed that any osteoporosis preventive behaviors would be difficult and not important.

In this study, the perceived benefits of exercise and calcium intake did outweigh the barriers. However, women had a positive view of both exercise and calcium intake, but they reported moderate perceived barriers for calcium intake and exercise, especially among women without family history were women consumed lower amounts of calcium compared to women with a family history. The women in both groups had a positive view of health motivation to prevent osteoporosis. Previous studies have found high-perceived benefits of exercise and calcium intake in young women, Gammage et al. [26] found higher perceived benefits of calcium and exercise in women that due to their higher perceived susceptibility and perceived severity. In contrast, Edmonds et al. [27] found that young women had high-perceived benefits of exercise and calcium intake and low perceived barriers to calcium intake and exercise with a positive view of health motivation to prevent osteoporosis.

There was also a positive correlation between calcium intake perceived susceptibility, perceived severity, perceived benefits of calcium intake and exercise in women with a family history. An inverse association was observed between perceived barriers of exercise and calcium intake in women who have a family history of osteoporosis. A study conducted among Iranian women showed a direct relationship between calcium intake and perceived susceptibility $(r=0.068, p=0.003)$, and a significant inverse relationship with perceived barriers $(r=$ 0.047, $\mathrm{p}=0.05$ ) [29]. Sayed-Hassan et al. [30] found that calcium intake and perceived barriers were significantly associated, but Edmonds et al. [27] found little perceived barriers to calcium intake, low correlation and not significant between calcium intake and perceived barriers to exercise $(r=0.041, p=0.217)$. However, cal- 
cium intake also had a low correlation to perceived benefits of calcium intake that did not reach statistical significance $(r=0.050, p=0.159)$.

The limitations of the study were only four health centers were included; also it is a descriptive cross sectional, which does not infer causal relationships. The convenience sample is not representative of the women outside Al-Hassa city; also the actual sample may be limited. Also, some of the other factors that were not explored in this study, such as socioeconomic differences related to knowledge, health beliefs, and some of the lifestyle habits.

\section{Conclusion}

The present study provides baseline data for further study among women in Al-Hassa city. This study indicates inadequate daily calcium intake in Saudi women and highlights the need for diet and life habit interventions to improve calcium intake and exercise, which may help to reduce the burden of osteoporosis in Saudi Arabia. The majority of women in both groups had a modest knowledge on osteoporosis prevention. Perceived severity of osteoporosis was lower among women without a family history. Practices towards preventing osteoporosis (exercising, smoking, daily exposing to sunlight, calcium and vitamin D supplement intake) are inadequate in both groups.

\section{References}

[1] Sadat-Ali, M., Al-Habdan, I., Al-Turki, H. and Azam, M. (2012) An Epidemiological Analysis of the Incidence of Osteoporosis and Osteoporosis-Related Fractures among the Saudi Arabian Population. Annals of Saudi Medicine, 32, 637-641.

[2] AlQuaiz, A., Kazi, A., Tayel, S., Shaikh, S., Al-Sharif, A. and Othman, S. (2014) Prevalence and Factors Associated with Low Bone Mineral Density in Saudi Women: A Community Based Survey. BMC Musculoskeletal Disorders, 15, 5-15. http://dx.doi.org/10.1186/1471-2474-15-5

[3] Al-Habdan, M., Sadat, M., Al-Muhanna, A., Al-Elq, H. and Al-Mulhim, A. (2009) Bone Mass Measurement Using Quantitative Ultrasound in Healthy Saudi Women. A Cross-Sectional Screening. Saudi Medical Journal, 30, 14261431.

[4] The International Osteoporosis Foundation (IOF). http://www.iofbonehealth.org/facts-statistics\#category-28

[5] Wahba, A., El-Shaheed, A., Tawheed, M., Mekkawy, A. and Arrafa, A. (2010) Osteoporosis Knowledge, Beliefs \& Behaviors among Egyptian Female Students. Proceeding of the 3rd International Conference of the Arab Society for Medical Research, Libya, 12-14 October 2010; JASMR, 5, 173-180.

[6] Al-Zu'bi, A., Almuhtaseb, N. and Amayreh, I. (2010) Osteoporosis Awareness in a Sample of Teenage Girls in Jordan, Jordan Medical Journal, 44, 420-426.

[7] Cline, R.R. and Worley, M.M. (2006) Osteoporosis Health Beliefs and Self-Care Behaviors: An Exploratory Investigation. Journal of American Pharmacists Association, 46, 356-364. http://dx.doi.org/10.1331/154434506777069534

[8] Orces, C.H., Casas, C., Lee, S., Garci-Cavazos, R. and White, W. (2003) Determinants of Osteoporosis Prevention in Low-Income Mexican-American Women. Southern Medical Journal, 96, 458-464. http://dx.doi.org/10.1097/01.SMJ.0000051905.38128.B4

[9] Winzenberg, T.M., Oldenburg, B., Frendin S. and Jones, G. (2003) The Design of a Valid and Reliable Questionnaire to Measure Osteoporosis Knowledge in Women: The Osteoporosis Knowledge Assessment Tool (OKAT). BMC Musculoskeletal Disorder, 4, 1-7. http://dx.doi.org/10.1186/1471-2474-4-1

[10] Hernandez-Rauda, R. and Martinez-Garcia, S. (2004) Osteoporosis-Related Life Habits and Knowledge about Osteoporosis among Women in El Salvador: A Cross-Sectional Study. BMC Musculoskeletal Disorder, 5, 29-46. http://dx.doi.org/10.1186/1471-2474-5-29

[11] Barzanji, A.T., Alamri, F.A. and Mohamed, A.G. (2013) Osteoporosis: A Study of Knowledge, Attitude and Practice among Adults in Riyadh, Saudi Arabia. Journal of Community Health, 38, 1098-1105. http://dx.doi.org/10.1007/s10900-013-9719-4

[12] Kim, K.K., Horan, M.L. and Gendler, P. (1991) Development and Evaluation of the Osteoporosis Health Belief Scale. Research in Nursing \& Health, 14, 155-163. http://dx.doi.org/10.1002/nur.4770140210

[13] World Health Organization (1998) Obesity: Preventing and Managing the Global Epidemic. Report of a World Health Organization Consultation on Obesity. WHO, Geneva.

[14] Memish, Z.A., El Bcheraoui, C., Tuffaha, M., Robinson, M., Daoud, F. and Jaber, S. (2014) Obesity and Associated Factors Kingdom of Saudi Arabia. Preventing Chronic Disease, 11, Article ID: 140236. 
http://dx.doi.org/10.5888/pcd11.140236

[15] Darwish, M.A., Al Turki, Z.A., Sabra, A.A. and Sebiany, A.M. (2014) Obesity among Females Attending Al-Qatif Health Care Centers, Eastern Saudi Arabia: Prevalence and Associated Factors. International Journal of Medical Science and Public Health, 3, 1144-1149. http://dx.doi.org/10.5455/ijmsph.2014.070720141

[16] Alshammari, K.F. (2014) Women Knowledge, Attitude and Practices about Osteoporosis Prevention "Riyadh Saudi Arabia”. World Journal of Medical Sciences, 11, 422-431.

[17] Bailey, R.L., Dodd, K.W. and Goldman, J.A. (2010) Estimation of Total Usual Calcium and Vitamin D Intakes in the United States. The Journal of Nutrition, 140, 817-822. http://dx.doi.org/10.3945/jn.109.118539

[18] World Health Organization (WHO) (2003) Prevention and Management of Osteoporosis. World Health Organization Technical Report Series, No. 921, 1-164.

[19] Rafraf, M. and Bazyun, B. (2010) Food Habits Related to Osteoporosis in Women in Iran. Health Promotion Perspectives, 1, 111-117.

[20] Ediriweera de Silva, R.E., Haniffa, M.R., Gunathillaka, K., Atukorala, I., Endahandige Fernando, D. and Perera, W. A. (2014) Descriptive Study of Knowledge, Beliefs and Practices Regarding Osteoporosis among Female Medical School Entrants in Sri Lanka. Asia Pacific Family Medicine, 13, 15. http://dx.doi.org/10.1186/s12930-014-0015-y

[21] Ho, S.C., Leung, P.C., Swaminathan, R., Chan, C., Chan, S.S.G., Fan, Y.K. and Lindsay, R. (1994) Determinants of Bone Mass in Chinese Women Aged 21 - 40 Years. II. Pattern of Dietary Calcium Intake and Association with Bone Mineral Density. Osteoporosis International, 4, 167-175. http://dx.doi.org/10.1007/BF01623064

[22] Patil, S.S., Hasamnis, A.A., Jena, S.K., Rashid, A.K. and Narayan, K.A. (2010) Low Awareness of Osteoporosis among Women Attending an Urban Health Center in Mumbai, Western India. Malaysian Journal of Public Health Medicine, 10, 6-13.

[23] Hurst, P.R. and Wham, C.A. (2006) Attitudes and Knowledge about Osteoporosis Risk Prevention: A Survey of New Zealand Women. Public Health Nutrition, 10, 747-753.

[24] Rafraf, M.A., Bazyun, B.B. and Afsharnia, F.C. (2009) Osteoporosis-Related Life Habits and Knowledge about Osteoporosis among Women in Tabriz, Iran. The International Medical Journal, 8, 17-21.

[25] Endicott, R.D. (2013) Knowledge, Health Beliefs, and Self-Efficacy Regarding osteoporosis in perimenopausal women. Journal of Osteoporosis, 2013, Article ID: 853531.

[26] Gammage, K., Gasparotto, J., Mack, D.E. and Klentrou, P. (2012) Gender Differences in Osteoporosis Health Beliefs and Knowledge and Their Relation to Vigorous Physical Activity in University Students. Journal of American College Health, 60, 58-64. http://dx.doi.org/10.1080/07448481.2011.570399

[27] Edmonds, E., Turne, L.W. and Usdan, S.L. (2012) Osteoporosis Knowledge, Beliefs, and Calcium Intake of college Students: Utilization of the Health Belief Model. Open Journal of Preventive Medicine, 2, 27-34. http://dx.doi.org/10.4236/ojpm.2012.21005

[28] Chang, S.F. (2006) A Cross Sectional Survey of Calcium Intake in Relation to Knowledge of Osteoporosis and Beliefs in Young Adult Women. International Journal of Nursing Practice, 12, 21-27. http://dx.doi.org/10.1111/j.1440-172X.2006.00546.x

[29] Jeihooni, A.K., Hidarnia, A., Kaveh, M., Hajizadeh, E. and Askari, A. (2014) Survey of Osteoporosis Preventive Nutritional Behaviors Based Health Belief Model in Sample of Iranian Women. Middle-East Journal of Scientific Research, 21, 595-601.

[30] Sayed-Hassan, R., Bashour. H. and Koudsi, A. (2013) Osteoporosis Knowledge and Attitudes: A Cross-Sectional Study among Female Nursing School Students in Damascus. Archives of Osteoporosis, 8, 1-8. http://dx.doi.org/10.1007/s11657-013-0149-9 